\section{Commentary: Health equity and enhanced recovery protocols: Mind the gap}

\author{
Virginia R. Litle, MD
}

In many surgical disciplines, enhanced recovery programs are integral components of the patient care experience. Key components include patient education, limiting preoperative fasting and intravenous fluids, early ambulation, and lower opioid use. The ultimate goals are to improve clinical outcomes as well as health care costs. ${ }^{1}$ Initially deemed a fast-track system for many specialties, colorectal surgeons in particular took the lead and subsequently the Enhanced Recovery After Surgery (ERAS) Society was established for all specialties. Formal guidelines for lung surgery were just recently published by an ERAS Society and the European Society of Thoracic Surgery consensus group ${ }^{2}$ as the general enthusiasm gained broader interest across the pond and in our specialty. Thoracic ERAS continues to vary between programs ${ }^{3}$ with a current debate about the role of the minimally invasive approach ${ }^{4,5}$ and, as Robinson and colleagues ${ }^{6}$ describe, with potential modifications of the preoperative regimen.

Robinson and colleagues ${ }^{6}$ summarize their successful experience with a nutrition-based ERAS protocol. The authors had great success ( $100 \%$ compliance!) in getting their lung resection patients to start the following protocol 5 days preoperatively: an immunonutrition drink thrice daily, probiotics daily, and then standard carbohydrate loading the night before. Patients and their health care system benefited: shorter lengths of stay, fewer complications, and lower hospital costs. Indeed this is an enticing expansion of thoracic ERAS and perhaps it will engage others. We must appreciate, however, that certain ERAS factors are surgeon-dependent, yet prehospital factors require patient

\footnotetext{
From the Division of Thoracic Surgery, Department of Surgery, Boston University School of Medicine, Boston, Mass.

Disclosures: The author reported no conflicts of interest.

The Journal policy requires editors and reviewers to disclose conflicts of interest and to decline handling or reviewing manuscripts for which they may have a conflict of interest. The editors and reviewers of this article have no conflicts of interest.

Received for publication July 16, 2020; revisions received July 16, 2020; accepted for publication July 17, 2020; available ahead of print July 19, 2020.

Address for reprints: Virginia R. Litle, MD, Division of Thoracic Surgery, Department of Surgery, Boston University, 88 E Newton St, Collamore 7380, Boston, MA 02118 (E-mail: Virginia.litle@bmc.org).

J Thorac Cardiovasc Surg 2021;162:721-2

$0022-5223 / \$ 36.00$

Copyright (c) 2020 by The American Association for Thoracic Surgery

https://doi.org/10.1016/j.jtcvs.2020.07.053
}

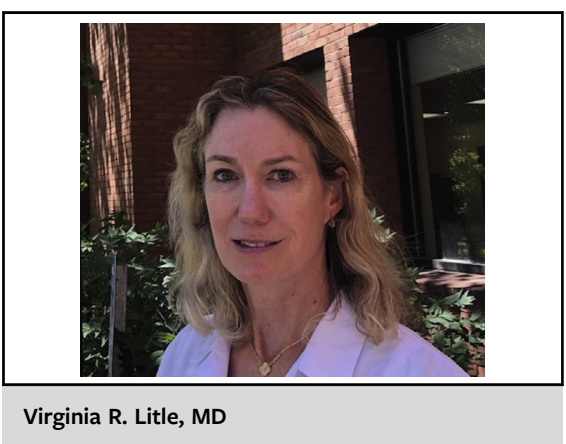

\begin{abstract}
CENTRAL MESSAGE
When expanding enhanced recovery protocols, implement components for engagement of vulnerable populations, including uninsured and racially and ethnically disparate patients.
\end{abstract}

engagement with a baseline level of financial and comprehension competence.

Health equity in procedures that optimize patient outcomes is imperative. Racial disparities in lung cancer survival already exist and contributing factors are disparate rates of potentially curative surgical resection for Blacks and Hispanics in particular ${ }^{7}$ and oncologic outcomes in general. ${ }^{8}$ Improvements in outcomes have been reported after implementation of ERAS in vulnerable populations; however, health disparities, including social, economic, and/or environmental disadvantages still persist. ${ }^{9}$

Approximately $25 \%$ of hospitals in the United States are categorized as safety-net hospitals. These so-called providers of last resort are where the uninsured and vulnerable populations-including immigrants, the mentally ill, and people addicted to opioids-receive care. ${ }^{10}$ Reduction in postoperative opioid use is a goal of ERAS and the importance of a universally accessible program cannot be understated. The preoperative components and challenges include patient education (barriers: language and literacy; solution: enhanced multilingual patient navigators, increased accessibility to technology for video televisits, and apps for patient education), nutrition (barriers: cost and access; solution: food banks and delivery services), smoking cessation (barriers: commitment to quit; solution: perplexing me still).

Thoracic ERAS has potential to improve racial/ethnic disparities in surgical outcomes; however, it also has potential to widen it. Do not increase the complexity and financial expense by converting the gap to a crevasse. Mind the gap 
and advance thoracic perioperative management with attention to all.

\section{References \\ 1. Ljungqvist O, Scott M, Fearon KC. Enhanced recovery after surgery: a review. JAMA Surg. 2017;152:292-8. \\ 2. Batchelor TJP, Rasburn NJ, Abdelnour-Berchtold E, Brunelli A, Cerfolio RJ, Gonzalez M, et al. Guidelines for enhanced recovery after lung surgery: recommen- dations of the Enhanced Recovery After Surgery (ERAS $®)$ Society and the European Society of Thoracic Surgeons (ESTS). Eur J Cardiothoracic Surg. 2019;55:91-115. \\ 3. Haywood N, Nickel I, Zhang A, Byler M, Scott E, Julliard W, et al. Enhanced recovery after thoracic surgery. Thorac Surg Clin. 2020;30:259-67. \\ 4. Krebs ED, Mehaffey JH, Sarosiek BM, Blank RS, Lau CL, Martin LW. Is less really more? Re-examining video-assisted thoracoscopic versus open lobectomy in the setting of an enhanced recovery protocol. J Thorac Cardiovasc Surg. September 13, 2019 [Epub ahead of print].}

5. Batchelor TJP, Ljungqvist O. A surgical perspective of ERAS guidelines in thoracic surgery. Curr Opin Anaesthesiol. 2019;32:17-22.

6. Robinson LA, Tanvetyanon T, Grubbs D, Robinson NA, Pierce CM, McCarthy K, et al. Preoperative nutrition-enhanced recovery after surgery (N-ERAS) protocol for thoracic neoplasms. J Thorac Cardiovasc Surg. 2021; 162:710-20.e1

7. Soneji S, Tanner NT, Silvestri GA, Lathan CS, Black W. Racial and ethnic disparities in early-stage lung cancer survival. Chest. 2017;152:587-97.

8. Farjah F, Wood DE, Yanez ND III, Vaughan TL, Symons RG, Krishnadasan B, et al. Racial disparities among patients with lung cancer who were recommended operative therapy. Arch Surg. 2009;144:14-8.

9. Marques IC, Wahl TS, Chu DI. Enhanced recovery after surgery and surgical disparities. Surg Clin North Am. 2018;98:1223-32.

10. Sutton JP, Washington RE, Fingar KR, Elixhauser A. Characteristics of safetynet hospitals; 2014. H-CUP Statistical Brief \#213. Available at: https://www. hcup-us.ahrq.gov/reports/statbriefs/sb213-Safety-Net-Hospitals-2014.jsp. Accessed July 25, 2020.
See Article page 710.

\section{Commentary: Enhanced recovery in thoracic surgery: You are what you eat?}

\author{
Daniel P. McCarthy, MD, MBA
}

The core principle of "enhanced recovery" is that perioperative care should be guided by evidence rather than tradition. Yet, converting this principle into practice is harder than it seems. Which evidence do you believe? Data from abdominal surgery may not be generalizable to thoracic patients, where pain is more severe and bowel function is less relevant. What specific protocols do you choose? Enhanced recovery programs typically implement bundled interventions across multiple domains. It is difficult to parse the relative contribution of each domain and decide which elements are essential. ${ }^{1}$ Even within key areas like pain

From the Division of Cardiothoracic Surgery, Department of Surgery, University of Wisconsin-Madison, Madison, Wis.

Disclosures: The author reported no conflicts of interest.

The Journal policy requires editors and reviewers to disclose conflicts of interest and to decline handling or reviewing manuscripts for which they may have a conflict of interest. The editors and reviewers of this article have no conflicts of interest.

Received for publication July 2, 2020; revisions received July 2, 2020; accepted for publication July 2, 2020; available ahead of print July 13, 2020.

Address for reprints: Daniel P. McCarthy, MD, MBA, Clinical Sciences Center, 600 Highland Ave, H4/318, Madison, WI 53792 (E-mail: mccarthyd@ surgery.wisc. edu).

J Thorac Cardiovasc Surg 2021;162:722-3

0022-5223/\$36.00

Copyright $(2020$ Published by Elsevier Inc. on behalf of The American Association for Thoracic Surgery

https://doi.org/10.1016/j.jtcvs.2020.07.019
Check for updates

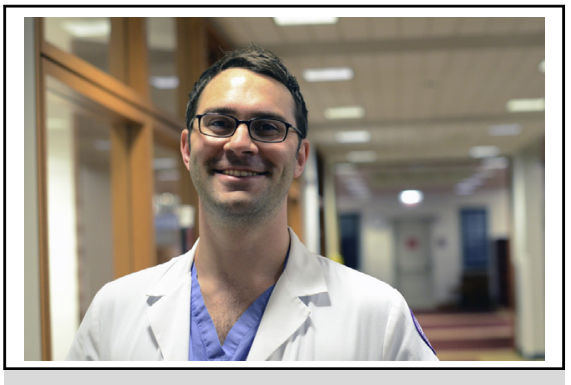

Daniel P. McCarthy, MD, MBA

CENTRAL MESSAGE

Incorporating a simple preoper-

ative nutrition intervention into

an enhanced recovery protocol

may improve outcomes after

thoracic cancer resections.

, there remains significant controversy around optimal regimens (regional anesthetic techniques, dosing of non-narcotic pain medications, etc). ${ }^{2}$ Finally, which outcomes matter to which stakeholders? ${ }^{3}$ Patients may appreciate the pain reduction from liposomal bupivacaine, but hospitals may not be willing to pay for it unless there is an associated decrease in length of stay. All of these questions are important to consider when crafting an enhanced recovery program.

Robinson and colleagues ${ }^{4}$ provide a focused contribution to the enhanced recovery literature in thoracic surgery. They describe the effect of a preoperative nutrition intervention 